\title{
ANALISIS PPM BERDASARKAN HASIL PBL
}

\author{
Fingki Indriani \\ Jurusan Kesehatan Masyarakat \\ Fakultas Kedokteran dan Ilmu Kesehatan \\ Universitas Islam Negeri Alauddin Makassar
}

Tempat PBL : Dusun Salassa, Desa Lebbotengae yang termasuk salah satu Dusun di Kecamatan Cenrana Kabupaten Maros Provinsi Sulawesi Selatan.

Angkatan : 2018

Posko : XI

\section{PERSIAPAN}

Kegiatan pengalaman belajar lapangan (PBL) II yang merupakan tindak lanjut dari kegiatan PBL I dimana di PBL II ini mahasiswa harus melakukan kegiatan intervensi berdasarkan baseline data yang didapatkan saat PBL I. Adapun pelaksanaan PBL II berlangsung dari tanggal 8 sampai 23 Desember 2020 dengan tujuan merumuskan prioritas masalah dan melaksanakan intervensi dari prioritas masalah yang telah ditentukan berdasarkan baseline data.

Berdasarkan data yang kami peroleh dari hasil wawancara kepada warga Dusun Salassa dengan menggunakan kuesioner dan aplikasi ODK pada PBL I, kami sudah dapat merumuskan beberapa indikator masalah yang kami susun dalam beberapa prioritas masalah yang akan menjadi program kerja kami selama PBL II yang merupakan wujud intervensi kami terhadap masalah yang kami prioritaskan atau utamakan.

Beberapa indikator masalah kesehatan yang kami temukan pada PBL I berdasarkan hasil wawancara yaitu:

- Masalah Penanganan Sampah

- Masalah kepemilikan SPAL

- Masalah kepemilikan tempat sampah

- Pengetahuan tentang HIV/AIDS 
Metode yang digunakan dalam menentukan prioritas masalah adalah dengan menggunakan metode CARL dimana $\mathrm{C}$ (Capability) yaitu ketersediaan sumber daya (dana, sarana dan peralatan) A (Accessibility) yaitu kemudahan, masalah yang ada mudah diatasi atau tidak. Kemudahaan dapat didasarkan pada ketersediaan metode/cara/teknoloi serta penunjang pelaksanaan. R (Readiness) yaitu kesiapan dari tenaga pelaksana maupun kesiapan sasaran. L (Leverage) yaitu seberapa besar pengaruh kriteria yang satu dengan yang lain dalam pemecahan masalah yang dibahas.

\section{PERENCANAAN}

Adapun yang menjadi kegiatan intervensi kami berdasarkan hasil prioritas masalah yaitu :

\section{INTERVENSI NON FISIK}

\section{Konseling mengenai Gizi Seimbang}

- Tujuan

Untuk meningkatkan pengetahuan masyarakat terkait gizi seimbang. Dari hasil konseling yang kami lakukan masih banyak masyarakat dusun Salassa yang tidak mengetahui terkait gizi seimbang. Dan ada beberpa diantara mereka yang hanya sekedar tau tentang 4 Sehat 5 Sempurna.

- Sasaran

Adapun sasaran dari kegiatan ini ditujukan warga di Dusun Salassa Desa Lebbotengae Kecamatan Cenrana yang memiliki Balita.

- Waktu

Kegiatan ini dilaksanakan pada hari Rabu, 16 Desember 2020 pukul 10.00 WITA dan 17.35 WITA.

- Tempat

Program ini dilaksanakan dirumah warga yang memiliki balita di Dusun Salassa Desa Lebbotengae, Kecamatan Cenrana Kabupaten Maros.

- Penanggung Jawab

Penanggung jawab dalam intervensi ini adalah Nurdina Fitra Adlia, Anita dan Mutmainnah.

- Hasil

Kegiatan konseling ini dilaksanakan dengan cara door to door kerumah RT yang memiliki balita mulai pukul 10.00 hingga pukul 17:35 WITA. Kami membagi tim menjadi 4 tim yang melakukan konseling dirumah yang berbeda. Awalnya kami 
berencana melakukan konseling ini, bertempat di aula desa. Akan tetapi, karena cuaca sehingga tidak ada warga yang datang. Maka, dari itu kami berinisiatif untuk melakukan door to door. Adapun jumlah keseluruhan rumah tangga yang kami beri konseling yaitu sebanyak 13 rumah tangga.

2. Konseling tentang pentingnya PMT

- Tujuan

Untuk meningkatkan pengetahuan masyarakat terkait pentingnya PMT.

- Sasaran

Adapun sasaran dari kegiatan ini ditujukan kepada RT di Dusun Salassa Desa Lebbotengae Kecamatan Cenrana yang memiliki Balita gizi kurang.

- Waktu

Kegiatan ini dilaksanakan pada hari Rabu, 16 Desember 2020 pukul 11.00 WITA.

- Tempat

Program ini dilaksanakan dirumah warga yang memiliki balita gizi kurang di Dusun Salassa Desa Lebbotengae, Kecamatan Cenrana Kabupaten Maros.

- Penanggung Jawab

Penanggung jawab intervensi ini adalah Sukmawati. B dan Mufti As siddiq.

- Hasil

Kegiatan konseling ini dilaksanakan dengan berkunjung kerumah RT yang memiliki balita gizi kurang pukul 11.00 WITA. Dimana, pada proses konseling kami didampingi oleh salah satu kader psoyandu. Adapun jumlah rumah tangga yang kami beri konseling yaitu sebanyak 1 rumah tangga berdasarkan data yang kami dapatkan dilapangan serta hasil analisis kami menggunakan WHO antro.

3. Pelatihan Kader Posyandu

- Tujuan

Untuk meningkatkan pengetahuan kader posyandu mengenai tugas dan wewenang kader posyandu, pengimplementasian lima meja di posyandu dan cara melakukan pengukuran. Karena berdasarkan sumber dari Puskesmas mengatakan bahwa dari seluruh kader posyandu yang ada di wilayah kerja puskesmas cenrana, kader posyandu dusun salassa belum pernah dilakukan pelatihan.

- Sasaran 
Adapun sasaran dari kegiatan ini ditujukan kepada kader posyandu di Dusun Salassa Desa Lebbotengae Kecamatan Cenrana, Kab. Maros.

- Waktu

Kegiatan ini dilaksanakan pada hari rabu, 22 Desember 2020 pukul 08:00 selesai.

- Tempat

Program ini dilaksanakan di aula Kantor Desa Lebbotengae, Kec. Cenrana, Kab. Maros.

- Penanggung Jawab

Penanggung jawab dalam kegiatan ini adalah Sukmawati. B dan Nurdina Fitra Adlia.

- Hasil

Kegiatan penyuluhan ini dilaksanakan di aula Kantor Desa Lebbotengae. Jumlah peserta yang ikut berpartisipasi dalam kegiatan pelatihan kader posyandu sebanyak 16 orang dengan 1 bidan desa dan 15 kader posyandu yaitu 5 kader posyandu Dusun Salassa, 5 kader Posyandu Dusun Parigi dan 5 kader Posyandu Dusun Tana Takko. kegiatan ini merupakan intervensi kolaborasi antar posko 10, 11 dan 12. Pada kegiatan ini, pemateri hanya membawakan 2 materi yaitu materi peran serta tugas kader posyandu dan materi serta praktek mengisi buku KIA. Alasan pemateri dari pihak puskesmas yang membawakan hanya 2 materi karena hari tim survei yang berkunjung ke puskesmas cenrana. Sehingga, petugas puskesmas segera balik ke puskesmas lagi. Akan tetapi, dia akan melanjutkan konseling tersebut dilain waktu.

\section{INTERVENSI FISIK}

1. Pemberian PMT Bagi Balita Gizi Kurang

- Tujuan

Untuk meningkatkan status gizi balita di Dusun Salassa Desa Lebbotengae Kec. Cenrana Kab. Maros. Kegiatan ini juga dilakukan agar mengurangi jumlah balita yang teridentifikasi sebagai gizi kurang di Dusun Salassa.

- Sasaran 
Adapun sasaran dari kegiatan ini ditujukan kepada RT yang memiliki balita dengan status gizi kurang di Dusun Salassa Desa Lebbotengae Kecamatan Cenrana, Kab. Maros.

- Waktu

Kegiatan ini dilaksanakan pada hari sabtu, 17 Desember 2020 pukul 14.00 WITA

- Tempat

Program ini dilaksanakan di rumah yang teridentifikasi gizi kurang.

- Penanggung Jawab

Penanggung jawab dalam kegiatan ini adalah Mufti As Siddiq dan Sukmawati. B

- Hasil

Kegiatan ini dilakukan dengan cara memberika PMT kepada keluarga balita yang berstatus gizi kurang. PMT ini diperoleh dari kerja sama dengan Puskesmas Cenrana, pemberian PMT ini dilakukan setiap tanggal 6 yang dimana PMT tersebut akan difasilitasi oleh Puskesmas Cenrana. Dalam pemberian PMT ini didampingi oleh kader posyandu Dusun Salassa dengan harapan bahwa akan melanjutkan kegiatan ini untuk kedepannya.

2. Pembenahan Posyandu

- Tujuan

Tujuan kegiatan ini yaitu untuk meningkatkan partisipasi masyarakat ke posyandu mencapai 60\%. Karena dari data sekunder yang didapatkan bahwa partisipasi masyarakat ke posyandu hanya sekitar $45 \%$. Hal ini disebabkan karena tidak terpenuhinya sarana dan prasarana di posyandu Dusun Salassa dan kurangnya pengetahuan masyarakat tentang pentingnya kegiatan posyandu.

- Sasaran

Adapun sasaran dari kegiatan ini ditujukan kepada fasilitas posyandu di Dusun Salassa, Desa Lebbotengae, Kec. Cenrana, Kab. Maros.

- Waktu

Kegiatan ini dilaksanakan pada tanggan 18 sampai 20 Desember 2020.

- Tempat 
Program ini dilaksanakan di posyandu mekar sari Dusun Salassa Desa Lebbotengae, Kec. Cenrana, Kab. Maros.

- Penanggung jawab

Penanggung jawab dalam kegiatan ini adalah Andi Fathyah Hanifah, Noviana dan Nuraqidatul Izzah Alimus.

- Hasil

Kegiatan ini dilakukan karena berdasarkan data sekunder yang didapatkan bahwa partisipasi masyarakat ke posyandu belum mencapai standar 60\%. Hal ini dapat dikarenakan tidak memadainya posyandu di Dusun Salassa hal ini dibuktikan dengan bangunan posyandu yang terlihat kumuh serta tidak tersedianya alat pengukuran. Sedangkan faktor lainnya adalah kurangnya pengetahuan masyarakat tentang pentignya posyandu. Pembenahan posyandu ini dilakukan dengan cara mengecat kembali fasilitas posyandu dan pemasangan poster-poster kesehatan, kegiatan pembenahan posyandu ini dilakukan oleh para kader posyandu dan masyarakat yang bertempat tinggal di dekat posyandu. Adapun poster-poster kesehatan diperoleh dari Puskemas Cenrana.

\section{PELAKSANAAN}

Adapun kegiatan-kegiatan yang dilaksanakan adalah sebagai berikut:

\section{INTERVENSI NON FISIK}

1. Konseling gizi seimbang

Berdasarkan intervensi yang telah dilakukan khususnya kegiatan konseling mengenai gizi seimbang maka didapatkan hasil analisis sebagai berikut. Karakteristik Responden Konseling Gizi Seimbang

Berikut adalah tabel karakteristik responden berdasarkan jenis kelamin yang diberikan Konseling tentang Gizi Seimbang di Dusun Salassa Desa Lebbotengae Kabupaten Maros

Tabel 4.1

Tabel Berdasarkan Distribusi Data Jenis Kelamin Responden Pada Konseling tentang Gizi Seimbang di Dusun Salassa Desa Lebbotengae Kecamatan Cenrana Kabupaten Maros

Tahun2020 


\begin{tabular}{|c|c|c|}
\hline Jenis kelamin & Jumlah (n) & Persen (\%) \\
\hline Laki-laki & 5 & $\mathbf{1 4 , 7}$ \\
\hline Perempuan & 29 & $\mathbf{8 5 , 3}$ \\
\hline Total & $\mathbf{3 4}$ & $\mathbf{1 0 0}$ \\
\hline
\end{tabular}

Sumber: Data Primer 2020

Berdasarkan tabel 4.1 distribusi data responden pada konseling tentang gizi seimbang sebesar 29 Responden $(85,3 \%)$ berjenis kelamin perempuan dan 5 Responden $(14,7 \%)$ berjenis kelamin laki-laki yang menjadi responden konseling tentang gizi seimbang.

2. Konseling tentang Pentingnya PMT

Berdasarkan intervensi yang telah dilakukan khususnya kegiatan Konseling tentang Pentingnya PMT didapatkan hasil analisis sebagai berikut. Karakteristik Responden konseling tentang pentingnya PMT

Berikut adalah tabel karakteristik responden berdasarkan jenis kelamin yang diberikan Konseling tentang Pentingnya PMT di Dusun Salassa Desa Lebbotengae Kabupaten Maros

Tabel 4.3

Tabel Berdasarkan Distribusi Data Jenis Kelamin Responden Pada Konseling tentang Pentingnya PMT di Dusun Salassa Desa Lebbotengae Kecamatan Cenrana Kabupaten Maros

Tahun 2020

\begin{tabular}{|c|c|c|}
\hline Jeniskelamin & Jumlah (n) & Persen (\%) \\
\hline Laki-laki & $\mathbf{0}$ & $\mathbf{0}$ \\
\hline Perempuan & 1 & 100 \\
\hline Total & 1 & 100 \\
\hline
\end{tabular}

Sumber: Data Primer 2020 
Berdasarkan tabel 4.3 distribusi data responden pada Konseling tentang Pentingnya PMT sebanyak 1 Responden (100\%) berjenis kelamin perempuan.

3. Pelatihan Kader Posyandu

Berdasarkan intervensi yang telah dilakukan pada kegiatan pelatihan kader posyandu didapatkan hasil analisis sebagai berikut:

Tabel 4.4

Tabel Berdasarkan Distribusi Data Jenis Kelamin Responden Pada Pelatihan Kader Posyandu di Desa Lebbotengae Kecamatan Cenrana Kabupaten Maros

Tahun 2020

\begin{tabular}{|c|c|c|}
\hline Jeniskelamin & Jumlah (n) & Persen (\%) \\
\hline Laki-laki & 0 & 0 \\
\hline Perempuan & 21 & 100 \\
\hline Total & 21 & 100 \\
\hline
\end{tabular}

Sumber: Data Primer 2020

Berdasarkan tabel 4.4 distribusi data responden pada pelatihan kader posyandu sebanyak 21 Responden (100\%) berjenis kelamin perempuan.

INTERVENSI FISIK

4. Pemberian PMT

Kegiatan ini dilakukan di rumah RT yang memiliki balita gizi kurang pada hari rabu tanggal 16 Desember 2020. Dalam pemberian PMT ini kami didampingi oleh salah satu kader posyandu dusun Salassa Desa Lebbotengae Kecamatan Cenrana Kabupaten Maros.

5. Pembenahan Posyandu

Kegiatan ini dilakukan di Posyandu Dusun Salassa. berdasarkan data sekunder yang didapatkan bahwa partisipasi masyarakat ke posyandu belum mencapai standar $60 \%$. Hal ini dapat dikarenakan tidak memadainya posyandu di Dusun Salassa hal ini dibuktikan dengan bangunan posyandu yang terlihat kumuh serta tidak tersedianya alat pengukuran. Sedangkan faktor lainnya adalah kurangnya pengetahuan masyarakat tentang pentingnya posyandu. Pembenahan posyandu ini dilakukan dengan cara mengecat kembali fasilitas posyandu dan pemasangan poster-poster kesehatan, kegiatan pembenahan posyandu ini dilakukan oleh para 
kader posyandu dan masyarakat yang bertempat tinggal di dekat posyandu. Adapun posterposter kesehatan diperoleh dari Puskemas Cenrana.

\section{FAKTOR PENDUKUNG DAN PENGHAMBAT SELAMA PELAKSANAAN}

Dalam menyelenggarakan suatu kegiatan, tidak menutup kemungkinan bahwa akan selalau ada factor pendukung dan penghambat. Faktor pendukung adalah faktor yang menunjang kita dalam mencapai tujuan yang telah direncanakan sebelumnya. Sedangkan faktor penghambat adalah factor yang menjadi penghalang keberhasilan dalam upaya penyelengaraan kegiatan. kedua fakor inilah yang kerab kita temui dalam melaksanakan suatu kegiatan.

Dinamika bermasyarakat sangat dirasakan betul oleh kami dalam setiap kegiatan yang dilaksanakan pada pengalaman belajar lapangan (PBL) II ini. Adapun beberapa faktor yang mempengaruhi sehingga kegiatan PBL II ini berjalan sesuai dengan yang diharapkan antara lain:

1. Faktor pendukung

a. Partisipasi masyarakat Dusun Salassa dalam kegiatan kami selama PBL II

b. Adanya dukungan dari pemerintah setempat, seperti pemerintahan kecamatan cenrana, puskesmas cenrana, dan pemerintahan desa lebbotengae serta aparat desa lainnya yang sangat membantu dalam kegiatan intervensi kami

c. Partisipasi bidan desa dan kader-kader posyandu Dusun Salassa dalam bertukar pikiran serta kontribusi dalam kelancaran program kerja yang dilakukan.

d. Kerja sama rekan-rekan PBL II lainnya yang telah memberikan masukan dan bertukar pikiran dengan kami

e. Keterbukaan, sikap ramah dan kerjasama dari tokoh masyarakat, pemuda/pemudi dan masyarakat di Dusun Salassa

f. Adanya bimbingan dari dosen pembimbing dan penanggung jawab lapangan yang memberikan arahan dan masukan selama PBL II

2. Faktor penghambat 
Ada beberapa faktor penghambat yang mempengaruhi sehingga kegiatan PBL II tidak berjalan sesuai dengan apa yang diharapkan yaitu:

a. Terdapat rumah warga yang sulit diakses karena terpencil dan jauh dari pemukiman sehingga kegiatan kami tidak berjalan sesuai waktu yang telah ditentukan.

b. Ada beberapa masyarakat yang masih sangat sulit di ajak untuk berpartisipasi dalam kegiatan kami, dan kesibukan masyarakat dalam bekerja sehingga membatasi proses tatap muka secara langsung antara kami dengan masyarakat Dusun Salassa.

c. Curah hujan yang tinggi di Dusun Salassa setiap hari menghambat kegiatan intervensi kami.

d. Walaupun sebenarnya ada kegiatan yang dapat dilakukan pada malam hari. Semua kegiatan intervensi kami dilakukan pada sing hari, karena kendala keamanan. Yang membuat pergerakan kami menjadi terbatas.

\section{EVALUASI}

Kegiatan yang pertama kali dilakukan dalam PBL II adalah menganalisis hasil data PBL I dengan data-data kesehatan dari Puskemas Cenrana, POSKESDES Lebbotengae dan Posyandu Mekar Sari. Kemudian selanjutnya mengadakan forum group discussion yang dilaksanakan pada tanggal 16 Desember 2020 yang dilaksanakan di aula kantor Desa.

Dalam menunjang pelaksanaan intervensi fisik maupun non fisik yang kami lakukan di Pengalaman Belajar Lapangan (PBL) 2, maka sangat penting untuk memperhatikan segala aspek aset yang terdapat di desa serta dusun yang menjadi tempat pelaksanaan Pengalaman Belajar Lapangan (PBL) . Adapun mobilisasi aset yang kami manfaatkan adalah :

- Aset/ kapasitas individu atau sumber daya manusia

a. Kepala Desa Lebbotengae

b. Kepala Dusun Salassa

c. Ketua RT dan RK

d. Imam Mesjid Babussalam Dusun Salassa

- Aset/kapasitas organisasi dan assosiasi

a. Posyandu Mekar Sari

b. Kelompok Karang Taruna

c. Kantor Desa Lebbotengae

- Aset/kapasitas fisik atau sumber daya alam 
a. Aula Desa Lebbotengae

b.Posyandu Mekar Sari

- Aset Sumber Daya Alam

a. Hasil Pertanian

b.Hasil Kebun

- Aset/kapasitas ekonomi

a. Sumbangsi dana dan peralatan dari masyarakat

b.Sumbangsi pemerintahan desa dan kader posyandu

Jumlah RT yang ikut berpartisipasi dalam kegiatan konseling pentingnya PMT bagi gizi buruk dan pemberian PMT sebanyak 1 RT karena hanya ada satu balita yang berstatus gizi buruk di Dusun Salassa.

Jumlah RT yang ikut berpartisipasi dalam kegiatan Konseling gizi seimbang bagi balita sebanyak 24 RT dari 24 keluarga yang memiliki balita di Dusun Salassa.

Jumlah peserta yang ikut berpartisipasi dalam kegiatan pelatihan kader posyandu sebanyak 16 orang dengan 1 bidan desa dan 15 kader posyandu yaitu 5 kader posyandu Dusun Salassa, 5 kader Posyandu Dusun Parigi dan 5 kader Posyandu Dusun Tana Takko.

Warga yang hadir di kegiatan pembenahan posyandu adalah 5 dari kader posyandu mekar sari dan warga sekitar yang bertempat tinggal di sekitar posyandu. 